Article

\title{
An Investigation into Incidences of Microbial Contamination in Cosmeceuticals in the UAE: Imbalances between Preservation and Microbial Contamination
}

\author{
Ammar Abdulrahman Jairoun 1,2,*(D), Sabaa Saleh Al-Hemyari ${ }^{1,3}$, Moyad Shahwan 4,5 and \\ Sa'ed H. Zyoud ${ }^{6,7}$ (D) \\ 1 Discipline of Social and Administrative Pharmacy, School of Pharmaceutical Sciences, \\ Universiti Sains Malaysia, Pulau Pinang 11500, Malaysia; drsabasaleh@hotmail.com \\ 2 Health and Safety Department, Dubai Municipality, Dubai 67, UAE \\ 3 Pharmacy Department, Ministry of Health and Prevention, Dubai 1853, UAE \\ 4 Department of Clinical Sciences, College of Pharmacy and Health Sciences, Ajman University, \\ Ajman 346, UAE; moyad76@hotmail.com \\ 5 Center of Medical and Bio-Allied Health Sciences Research, Ajman University, Ajman 346, UAE \\ 6 Poison Control and Drug Information Center (PCDIC), College of Medicine and Health Sciences, \\ An-Najah National University, Nablus 44839, Palestine; saedzyoud@yahoo.com \\ 7 Clinical Research Centre, An-Najah National University Hospital, Nablus 44839, Palestine \\ * Correspondence: Dr_ammar_91_@hotmail.com
}

Received: 18 October 2020; Accepted: 19 November 2020; Published: 24 November 2020

\begin{abstract}
In recent years, concern about certain personal care products and cosmetics suffering from microbial contamination has increased. In this research, we aimed to determine the types and incidence of the most common microorganisms found in unopened/unused personal care and cosmetic products in the United Arab Emirates (UAE) market. This research involved an analysis of 100 personal care products and cosmetics. For every product, microbial (Candida albicans, Staphylococcus aureus, aerobic mesophilic bacteria, Escherichia coli, yeast and mold, and Pseudomonas aeruginosa) contamination was assessed, and levels were compared with the guidelines used in Europe. Of the total samples, 15\% (95\% CI: 0.79-22.1) were contaminated by aerobic mesophilic bacteria compared to the maximum microbial limit of $1000 \mathrm{CFU} / \mathrm{g}$. In addition, 13\% (95\% CI: 0.63-19.7) of the samples were contaminated with yeast and mold compared to the maximum microbial limit of $1000 \mathrm{CFU} / \mathrm{g}$. Of all samples, nine (9\%) were contaminated with both aerobic mesophilic bacteria and yeast and mold. However, none of the tested samples were contaminated with Escherichia coli, Staphylococcus aureus, Candida albicans, or Pseudomonas aeruginosa. Manufacturers of cosmetics and personal care products should be developing and implementing best practices regarding quality control/quality assurance in partnership with government regulators. Additionally, there should be greater control of the quality and safety of this type of product regarding good manufacturing practice (GMP), regulation, research, education, and the reporting of adverse events.
\end{abstract}

Keywords: microbial contamination; cosmeceuticals; cosmetovigilance; personal care; compliance behaviors

\section{Introduction}

Personal care products/cosmetics are popular across the globe and can be easily purchased, with no need for a prescription. This means that these products are not under the same strict regulations as those of prescription medicines. Cosmetics include any substance designed to be applied to the 
exterior of the human body with the intention of altering a person's appearance, cleaning the body, perfuming the body, maintaining the skin, addressing any body odor, and/or offering skin protection [1]. Because the skin and its defenses are capable of protecting the body against external substances, there is usually no requirement for cosmetics to be aseptic [2].

Cosmeceuticals are functional cosmetic products that provide features that extend beyond the conventional purpose of enhancing or scenting skin. However, while they claim to deliver tangible benefits, they are not formally recognized from a regulatory perspective in the United States and are viewed in the same light as alternative cosmetics [3]. Many dermatologists hold the view that cosmeceuticals can improve the appearance of the skin beyond that possible using standard cosmetics because they incorporate biologically active ingredients that can penetrate below the skin barrier to improve the health of the skin [4]. Cosmeceuticals combine active ingredients with a topical mechanism that serves to preserve the integrity of the active ingredient while delivering it in a biologically viable manner, accessing the target location in an adequate way to achieve a given effect. The topical employed also needs to have the ability to allow the active ingredient to be released from the carrier vehicle. In light of the lack of the regulatory acceptance of cosmeceuticals, there is a need for an efficacy assessment to be performed to verify the effectiveness of cosmeceuticals.

Although most cosmetic/personal care products are not harmful, recently, numerous concerns have been voiced regarding product quality and the marketing of such products. The manufacturing and sale of cosmetic/personal care products should undergo strict monitoring and regulation, and data should be collected and evaluated in relation to any adverse effects caused by them to make them safer for use. A significant concern regarding the quality/safety of cosmetic products is that the product can become spoiled by contamination with microorganisms, which can pose significant health risks for users $[5,6]$.

The skin barrier ceases to function with certain inflammatory dermatoses, such as atopic dermatitis; this is also the case where mechanical trauma or burns have been experienced. In these instances, the dangers of infection are significantly increased when the subject uses a cosmetic that has been microbially contaminated. Elderly people, children (below the age of three), and those whose immune systems are compromised are especially vulnerable to such contamination [7]. Because the skin in the periocular region is particularly delicate, products intended for application on or around the eyes are of particular concern [2].

Cosmetics can become microbially contaminated in two instances: (1) When manufactured or placed in a container and (2) when the consumer uses the product. In the first instance, the manufacturer must take steps to prevent microbial contamination so that the product is of the specified quality and consumer safety is protected. When the product is in use, consumers have a responsibility to keep it safe, e.g., by following the instructions for safe storage [2]. If cosmetic creams contain microorganisms, either from the manufacturing process or due to poor handling by users, this may cause a health hazard. Researchers have isolated a range of pathogenic microorganisms found in cosmetics [8].

One concerning issue is that cosmetics are not provided with production and/or expiration dates, which is surprising given that the preservatives used in cosmetics can degrade over time. In addition, cosmetics contain growth factors, organic and inorganic compounds, and essential minerals, and they are often stored under humid conditions, e.g., bathrooms, allowing microorganisms to flourish [9].

Cosmetic/personal care products sold in the United Arab Emirates (UAE) are generally tested as part of the consumer standards process, with regulators checking products for microbial contamination in the laboratory to make sure that there is no microbial growth in the product. Regulators also check that all products contain ingredients specified on their labels. One element of being approved for sale is that manufacturers provide a declaration that they have tested the product, that it does not have any microbial contamination, and that it is fully compliant with health and safety regulations. Guidelines specify that every new batch of products offered on the market should be routinely tested for microbial contamination. Such monitoring is essential as products are increasingly being recalled, and most recalls are due to contamination with potentially pathogenic microorganisms [8]. 
Further information about how these products become contaminated is required [10]. The objective of this study was to determine the type and incidence of predominant microorganisms and microbial contamination in unused cosmetic and personal care products (finished products) at the point of sale in the UAE.

\section{Methodology/Materials}

\subsection{Collection of Samples (Sampling Methodology)}

A search was performed on local business directories to find all retail outlets that offer cosmetic/personal care products. The business directories list all healthcare retailers, pharmacies, and parapharmacies in the UAE. In total, 2183 were listed, and a sampling framework was created using an Excel spreadsheet that contained all of the information required, e.g., the name of the business, address, telephone number, and email. The study sample was selected using standard random sampling methods employing the business ID numbers, which were categorized by location and type. For each location selected, a package of every cosmetic/personal care product being sold was randomly selected with no screening for the place of manufacturing. All items were given code reference numbers so that they could be tracked and to prevent duplication. The following details were recorded for each sample: The product name, brand name, type of item, country of origin/manufacturer, subcategory, dosage form, batch number, bar code, size/volume, recommended dosage, and location of the retail outlet supplying the particular product. If an identical product was stocked by multiple outlets (i.e., identical product name, manufacturer, formulation, barcode, and size/volume), the earliest selected product underwent testing, and duplicate products were returned. Products sharing the same name but had different manufacturers or more than one format (e.g., emulsion and cream) were classified as individual products, and both underwent testing. Each selected product underwent laboratory analysis on the same day it was chosen.

\subsection{Standards and Guidelines Used for the Detection of Microorganisms}

The BS EN ISO 21150:2015 standard was used to detect and identify the specified microorganisms. This procedure, which was applied to enumerate the microorganisms from cosmetic products, involves direct colony counts and enrichment culturing. In direct colony counts, we could count the total aerobic mesophilic bacteria (total aerobic microbial count and total yeast and mold count). In enrichment culturing, we could detect specified harmful pathogens and their presence, such as the detection of Escherichia coli, Pseudomonas aeruginosa, Staphylococcus aureus, and Candida albicans. All the chemicals used were of analytical grade and purchased from Sigma-Aldrich, USA.

\subsection{Enumeration of Aerobic Mesophilic Bacteria}

Based on the solubility of the product, enumeration was performed using the pour plate method or membrane filtration method. The pour plate method utilized $1 \mathrm{~g} / 1 \mathrm{~mL}$ of the product transferred to $9 \mathrm{~mL}$ of diluent (MLB), which was mixed well until the sample dissolved. In the case of water-insoluble products, we transferred a $1 \mathrm{~g} / 1 \mathrm{~mL}$ of sample to $9 \mathrm{~mL}$ of MLB containing $0.1 \%$ polysorbate 80 (neutralizer) and mixed it well. From this preparation, $1 \mathrm{~mL}$ of each sample was plated on a sterile $90 \mathrm{~mm}$ Petri dish in duplicate and pour plated with $20 \mathrm{~mL}$ of MLA for enumeration of the aerobic mesophilic bacteria. The MLA plates were incubated at $32.5 \pm 2.5^{\circ} \mathrm{C}$ for 3 to 5 days, and we calculated the number of CFUs per $\mathrm{mL}$ or per $\mathrm{g}$ of the product and reported the results.

\subsection{Enumeration of Yeast and Mold}

Based on the solubility of the product, enumeration was performed using the pour plate method or membrane filtration method. The pour plate method utilized $1 \mathrm{~g} / 1 \mathrm{~mL}$ of the product transferred to $9 \mathrm{~mL}$ of diluent (MLB), which was mixed well until the sample dissolved. In the case of water-insoluble products, we transferred $1 \mathrm{~g} / 1 \mathrm{~mL}$ of sample to $9 \mathrm{~mL}$ of MLB containing $0.1 \%$ polysorbate 80 (neutralizer) 
and mixed it well. From this preparation, $1 \mathrm{~mL}$ of each was plated on a sterile $90 \mathrm{~mm}$ Petri dish in duplicate, with $20 \mathrm{~mL}$ of SDCA for enumeration of the yeast and mold. For known or noncontaminated bacterial products, SDA medium was used. The media plates were incubated at $255 \pm 2.5^{\circ} \mathrm{C}$ for 3 to 5 days, and we calculated the number of CFUs per $\mathrm{mL}$ or per $\mathrm{g}$ of the product and reported the results.

\subsection{Detection of Escherichia coli}

First, $1 \mathrm{~g} / 1 \mathrm{~mL}$ of the product was transferred to $9 \mathrm{~mL}$ of diluent (MLB) and incubated at $30-35^{\circ} \mathrm{C}$ for 20-72 h. After completion of the enrichment broth, incubation of the subculture on a plate of Macconkey agar at $30-35{ }^{\circ} \mathrm{C}$ was performed for 18 to $72 \mathrm{~h}$. The growth of brick red colonies with a surrounding zone of precipitated bile on the Macconkey agar indicated the presence of Escherichia coli. This was confirmed by an identification test using Indole and EMB agar. The confirmation test for Escherichia coli was the indole test. A loop full of culture was transferred to $5 \mathrm{~mL}$ of sterile tryptone broth and incubated at $42-44^{\circ} \mathrm{C}$ for $24 \mathrm{~h}$. After incubation, $0.5 \mathrm{~mL}$ of Kovac's reagent was added to each tube, shaken well, and allowed to stand for $10 \mathrm{~min}$. If any red color was observed in the reagent layer, indole was present, which confirmed the possible presence of Escherichia coli. From the Macconkey agar subculture, a loop full was placed on EMB agar and incubated for $18-24 \mathrm{~h}$ at $30-35^{\circ} \mathrm{C}$. E. coli colonies were dark, centered, and flat, with or without a metallic sheen. We performed Gram staining and found Gram-negative rods and motile and smooth colonies.

\subsection{Detection of Staphylococcus aureus}

First, $1 \mathrm{~g} / 1 \mathrm{~mL}$ of the product was transferred to $9 \mathrm{~mL}$ of diluent (MLB) and incubated at $30-35^{\circ} \mathrm{C}$ for 20-72 h. After completion of the enrichment broth, incubation of the subculture on a plate of Baired Parker agar was performed and incubated at $30-35{ }^{\circ} \mathrm{C}$ for 18 to $24 \mathrm{~h}$. Black, shiny colonies surrounded by clear zones were observed. Further confirmation was performed using the catalase test, coagulase test, and Gram staining. Staphylococcus aureus is a Gram-positive coccus, catalase positive, and coagulase positive.

\subsection{Detection of Pseudomonas aeruginosa}

First, $1 \mathrm{~g} / 1 \mathrm{~mL}$ of the product was transferred to $9 \mathrm{~mL}$ of diluent (MLB) and incubated at $30-35^{\circ} \mathrm{C}$ for 20-72 h. After completion of the enrichment broth, incubation of the subculture on a plate of cetrimide agar was performed, and the plate was incubated at $30-35^{\circ} \mathrm{C}$ for 18 to $24 \mathrm{~h}$. Yellow to green colonies were fluorescent under UV. Further confirmation was performed by the oxidase test and Gram staining. Pseudomonas aeruginosa is a Gram-negative and oxidase-positive bacterium, allowing for the detection of pycocyanin in Pseudomonas agar.

\subsection{Detection of Candida albicans}

First, $1 \mathrm{~g} / 1 \mathrm{~mL}$ of the product was transferred to $9 \mathrm{~mL}$ of diluent (MLB) and incubated at $30-35^{\circ} \mathrm{C}$ for 20-72 h. After completion of the enrichment broth, incubation of the subculture on a plate of Sabouraud Chloramphenicol agar was performed, and the plate was incubated at $30-35^{\circ} \mathrm{C}$ for 18 to $24 \mathrm{~h}$. Candida albicans produces white to beige colonies on media. The presence of this fungus was also confirmed by a germ tube test using horse serum.

\subsection{Reporting of Values}

The total bacterial count and total fungal count are reported as CFU/g or $\mathrm{mL}$, accounting for a dilution factor, and the detection parameter is reported as present or absent/g.

\subsection{Quality Control and Assurance}

All the media prepared were checked for sterility and contamination, and a quality control evaluation was performed with suitable positive and negative control strains of the respective media. 


\subsection{Ethical Considerations}

The study was awarded approval from the Institutional Review Board of An-Najah National University (reference number Phd/3/20/3).

\section{Statistical Analysis}

The data were analyzed using SPSS version 24 (Chicago, IL, USA). Percentages and frequencies were used to summarize the qualitative variables. The concentrations of microbial contamination (mold and yeast, Staphylococcus aureus, Candida albicans, Pseudomonas aeruginosa, Escherichia coli, and aerobic mesophilic bacteria) were measured and checked against European guidelines (Table 1). The incidence of microbial contamination was classified as the proportion of the product that exceeded the maximum permitted microbiological level for any of the pathogens tested. Chi-square and Fisher exact tests were employed to study the prevalence of microbial contamination in accordance with the product characteristics. The statistically significant boundary was set at $p<0.05$.

Table 1. Number and percentage of cosmetics and personal care product characteristics $(n=100)$.

\begin{tabular}{cccc}
\hline Characteristics & Groups & Frequency & Percentage \\
\hline \multirow{5}{*}{ Categories } & Body care & 39 & $39 \%$ \\
& Eye care & 8 & $8 \%$ \\
& Face and neck care & 21 & $21 \%$ \\
& Hair and scalp care & 21 & $21 \%$ \\
& Oral hygiene products & 11 & $11 \%$ \\
\hline \multirow{5}{*}{ Country of origin } & China & 9 & $9 \%$ \\
& EU & 15 & $15 \%$ \\
& India & 14 & $14 \%$ \\
& Korea & 8 & $8 \%$ \\
& The Middle East & 10 & $10 \%$ \\
& UAE & 32 & $32 \%$ \\
\hline
\end{tabular}

\section{Results}

\subsection{Sample Description}

A total of 100 cosmetics and personal care products were analyzed in this study. Of the 100 samples, 39 (39\%) were body care preparations, 8 (8\%) were eye care preparations, $21(21 \%)$ were face and neck care preparations, 21 (21\%) were hair and scalp care preparations, and $11(11 \%)$ were oral hygiene products. Regarding the country of origin, 9 (9\%) were manufactured in China, $15(15 \%)$ in the EU, $14(14 \%)$ in India, $8(8 \%)$ in Korea, $10(10 \%)$ in the Middle East, $32(32 \%)$ in the United Arab Emirates, and $12(12 \%)$ in the United States (Table 1$)$.

\subsection{Evaluation of the Incidence of Bacterial and Fungal Contamination in the Cosmetics and Personal Care Products}

Table 2 summarizes the number of test results in which the measured colony-forming units were below the limit of detection (LOD). The incidence of microbial contamination is summarized in Table 3. These are the proportions of cosmetics and personal care products that were contaminated with microorganisms. Of all the samples, 15\% (95\% CI: 0.79-22.1) were contaminated by aerobic mesophilic bacteria compared to the maximum microbiological limit of $1000 \mathrm{CFU} / \mathrm{g}$. Additionally, 13\% (95\% CI: $0.63-19.7)$ of the samples were contaminated with yeast and mold compared to the maximum microbiological limit of $1000 \mathrm{CFU} / \mathrm{g}$. Of all samples, 9 (9\%) were contaminated by both aerobic mesophilic and yeast and mold. However, none of the tested samples were contaminated with Escherichia coli, Staphylococcus aureus, Candida albicans, or Pseudomonas aeruginosa. The overall incidence 
of microbial contamination was 19\% (95\% CI: 11.2-26.8). The estimated microbial contamination for the 100 products is presented graphically in histograms (Figures 1 and 2). The relevant microbiological maximum limits are displayed as vertical "cut-off" limits. The results of the microbial contamination categorized by sample characteristics for each sample are provided in Table 4.

Table 2. Distribution of cosmetic products that contained the tested microorganisms below the limit of detection $(n=100)$.

\begin{tabular}{ccc}
\hline \multirow{2}{*}{ Microorganism Type } & Number of Cosmetics with Microorganisms under the LOD \\
\cline { 2 - 3 } & Frequency & Percentage \\
\hline Aerobic mesophilic bacteria & 80 & $80 \%$ \\
Yeast and mold & 82 & $82 \%$ \\
Escherichia coli & 100 & $100 \%$ \\
Staphylococcus aureus & 100 & $100 \%$ \\
Candida albicans & 100 & $100 \%$ \\
Pseudomonas aeruginosa & 100 & $100 \%$ \\
\hline
\end{tabular}

Table 3. Estimation of the microbial contamination rate in the sampled cosmetics and personal care products $(n=100)$.

\begin{tabular}{|c|c|c|c|c|c|}
\hline \multirow{3}{*}{ Microorganism Type } & \multirow{3}{*}{$\begin{array}{l}\text { Microbiological } \\
\text { Maximum Limits }\end{array}$} & \multicolumn{4}{|c|}{ Cosmetics Exceeding the Maximum Limit } \\
\hline & & \multirow{2}{*}{$\mathbf{N}$} & \multirow{2}{*}{$\%$} & \multicolumn{2}{|c|}{$95 \% \mathrm{CI}$} \\
\hline & & & & Lower & Upper \\
\hline Aerobic mesophilic bacteria & $1000 \mathrm{CFU} / \mathrm{g}$ & 15 & $15 \%$ & 0.79 & 22.1 \\
\hline Yeast and mold & $1000 \mathrm{CFU} / \mathrm{g}$ & 13 & $13 \%$ & 0.63 & 19.7 \\
\hline Escherichia coli & Absence & ND & ND & \multicolumn{2}{|c|}{ ND } \\
\hline Staphylococcus aureus & Absence & ND & ND & \multicolumn{2}{|c|}{ ND } \\
\hline Candida albicans & Absence & ND & ND & \multicolumn{2}{|c|}{ ND } \\
\hline Pseudomonas aeruginosa & Absence & ND & ND & \multicolumn{2}{|c|}{ ND } \\
\hline
\end{tabular}

Maximum allowable limits according to BS EN ISO 21150:2015. ND, not deleted.

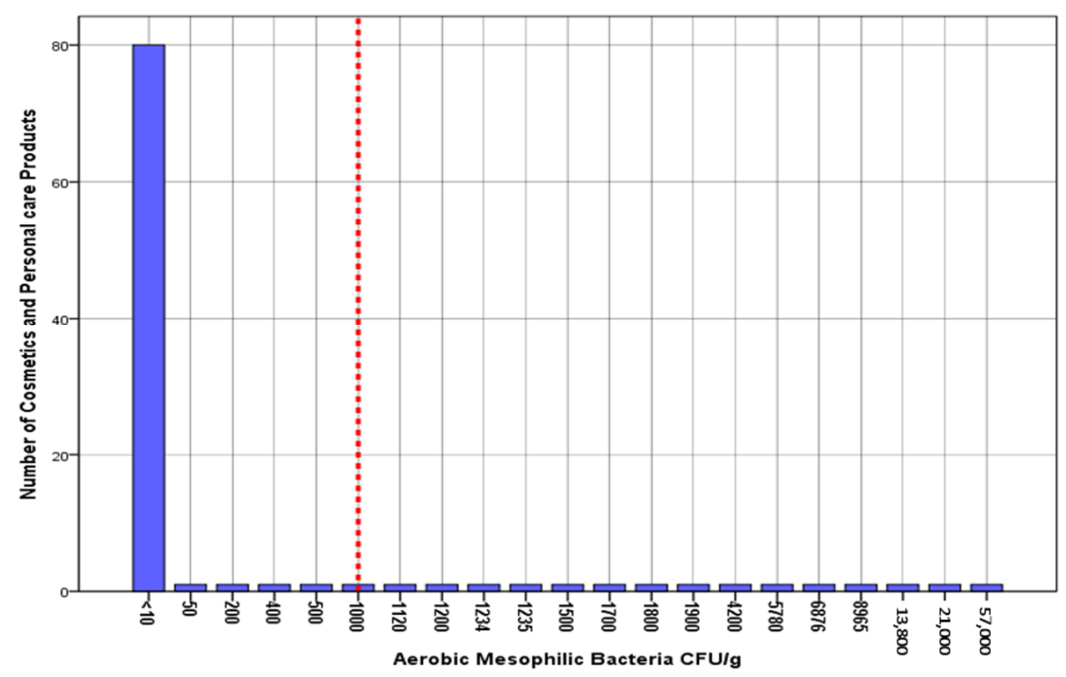

Figure 1. Histogram of the estimated aerobic mesophilic bacteria (CFU/g) for cosmetics and personal care products $(n=100)$. The vertical dashed line shows the microbiological maximum limits according to BS EN ISO 21150:2015. 


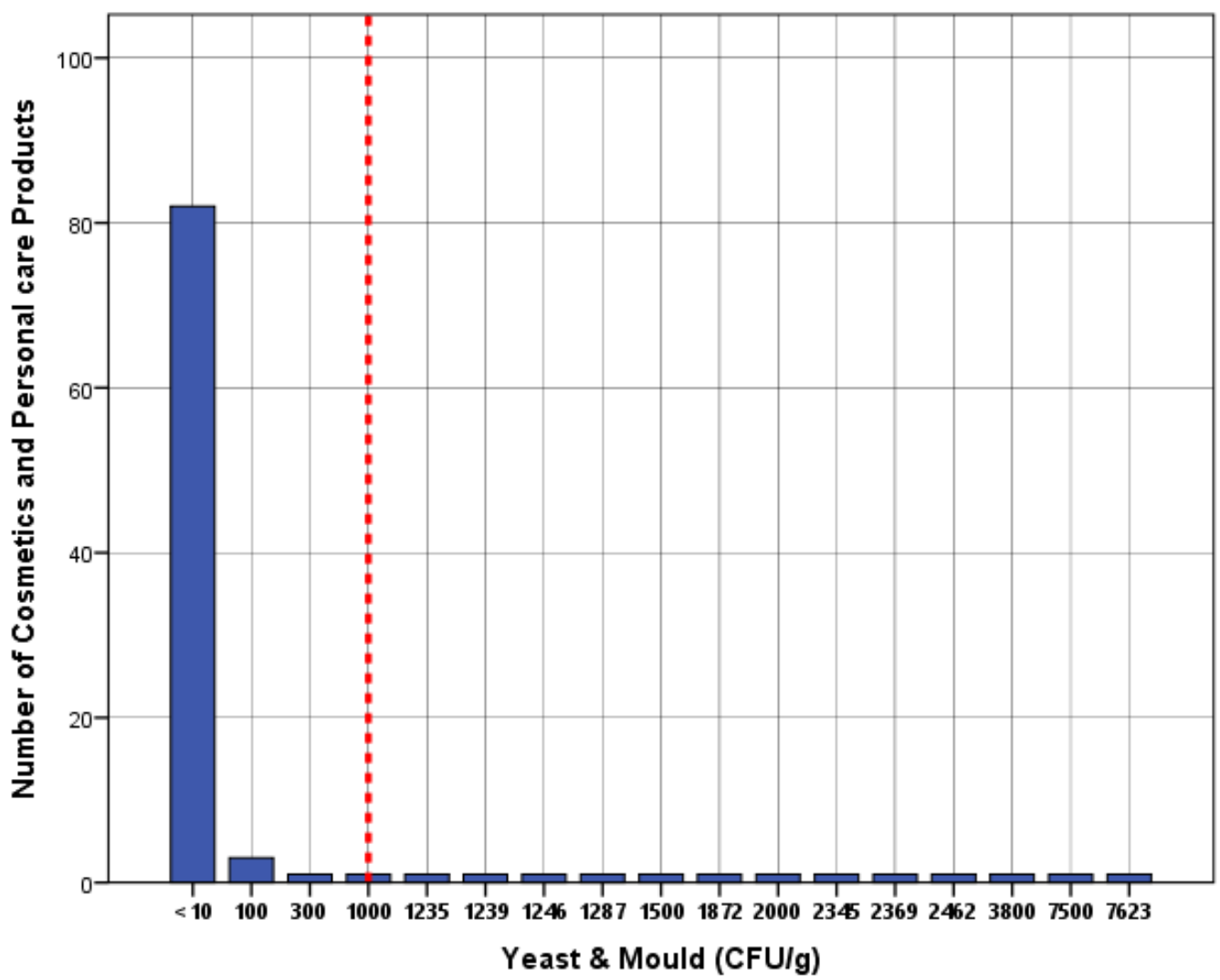

Figure 2. Histogram of the estimated yeast and mold (CFU/g) for cosmetics and personal care products $(n=100)$. The vertical dashed line shows the microbiological maximum limits according to BS EN ISO 21150:2015.

\subsection{Comparison of Microbial Contamination According to Sample Characteristics}

Table 5 shows the distribution of microbial contamination according to the sample characteristics. The table also provides the estimates with the $p$-values. These $p$-values were obtained from the results of the chi-square and Fisher's exact tests.

Comparisons of the groups did not reveal any significant differences in relation to microbial contamination.

Although not significant, the incidence of microbial contamination with aerobic mesophilic bacteria was higher for body care preparations $(20.5 \%)$ and hair and scalp care $(19 \%)$ than for the other categories of cosmetics. Moreover, the incidence of microbial contamination by yeast and mold was higher for oral hygiene products $(18.2 \%)$ and body care preparations $(15.4 \%)$ than for the other categories of cosmetics. Regarding the country of origin, products manufactured in the Middle East (30.0\%), India (28.6\%), and the USA (25.0\%) were more susceptible to contamination with aerobic mesophilic bacteria than those manufactured in the other studied places. In addition, products manufactured in the USA (33.3\%) and Middle East (20\%) were more likely to be contaminated by yeast and mold than by the other contaminants. 
Table 4. List of tested cosmetics and personal care products according to microbial contamination and sample characteristics.

\begin{tabular}{|c|c|c|c|c|c|c|c|}
\hline Name of the Product & Main Category & Country of Origin & $\begin{array}{l}\text { Staphylococcus } \\
\text { aureus (per g) }\end{array}$ & $\begin{array}{l}\text { Yeast and } \\
\text { Mold CFU/g }\end{array}$ & $\begin{array}{c}\text { Candida } \\
\text { albicans (per g) }\end{array}$ & $\begin{array}{c}\text { Aerobic Mesophilic } \\
\text { Bacteria CFU/g }\end{array}$ & $\begin{array}{l}\text { Pseudomonas } \\
\text { aeruginosa (per g }\end{array}$ \\
\hline Body lotion & Body care preparation & UAE & ND & $<10$ & ND & $<10$ & ND \\
\hline Facial cleanser & Face and neck care & UAE & ND & $<10$ & ND & $<10$ & ND \\
\hline Petroleum jelly & Body care preparation & UAE & ND & $<10$ & ND & $<10$ & ND \\
\hline Petroleum jelly & Body care preparation & UAE & ND & $<10$ & ND & $<10$ & ND \\
\hline Henna & Hair and scalp care & India & ND & 100 & ND & 500 & ND \\
\hline Henna & Hair and scalp care & India & ND & 7500 & ND & 57,000 & ND \\
\hline Herbal henna & Hair and scalp care & India & ND & 3800 & ND & 13,800 & ND \\
\hline Shampoo & Hair and scalp care & UAE & ND & $<10$ & ND & $<10$ & ND \\
\hline Hair crème & Hair and scalp care & UAE & ND & $<10$ & ND & $<10$ & ND \\
\hline Hair styling gel & Hair and scalp care & $\mathrm{EU}$ & ND & $<10$ & ND & $<10$ & ND \\
\hline Shower gel & Body care preparation & EU & ND & $<10$ & ND & $<10$ & ND \\
\hline Face moisturizing cream & Face and neck care & UAE & ND & 2369 & ND & 6876 & ND \\
\hline Facial scrub & Face and neck care & UAE & ND & $<10$ & ND & $<10$ & ND \\
\hline Body crème milk & Body care preparation & USA & ND & 1500 & ND & 1235 & ND \\
\hline Body wash & Body care preparation & EU & ND & $<10$ & ND & $<10$ & ND \\
\hline Hair styling gel & Hair and scalp care & Korea & ND & $<10$ & ND & $<10$ & ND \\
\hline Hair oil & Hair and scalp care & UAE & ND & $<10$ & ND & $<10$ & ND \\
\hline Eyeliner & Eye care & UAE & ND & $<10$ & ND & 50 & ND \\
\hline Hair oil & Hair and scalp care & $\mathrm{EU}$ & ND & $<10$ & ND & $<10$ & ND \\
\hline Moisturizing body cream & Body care preparation & UAE & ND & $<10$ & ND & $<10$ & ND \\
\hline Smooth hair cream & Hair and scalp care & India & ND & $<10$ & ND & $<10$ & ND \\
\hline Vaseline body butter & Body care preparation & UAE & ND & $<10$ & ND & $<10$ & ND \\
\hline Eyeliner & Eye care & UAE & ND & $<10$ & ND & $<10$ & ND \\
\hline Moisturizing body emulsion & Body care preparation & China & ND & $<10$ & ND & $<10$ & ND \\
\hline Facial nourishing cleanser & Face and neck care & China & ND & $<10$ & ND & $<10$ & ND \\
\hline Mouthwash & Oral hygiene product & USA & ND & $<10$ & ND & $<10$ & ND \\
\hline Vaseline body cream & Body care preparation & China & ND & $<10$ & ND & $<10$ & ND \\
\hline Face toner & Face and neck care & China & ND & $<10$ & ND & $<10$ & ND \\
\hline Petroleum jelly & Body care preparation & UAE & ND & $<10$ & ND & $<10$ & ND \\
\hline Fair cream & Hair and scalp care & India & ND & $<10$ & ND & $<10$ & ND \\
\hline $\begin{array}{c}\text { Anti-stretch-mark } \\
\text { moisturizing body cream }\end{array}$ & Body care preparation & Korea & ND & $<10$ & ND & $<10$ & ND \\
\hline $\begin{array}{l}\text { Anticellulite stretch mark } \\
\text { firming body cream }\end{array}$ & Body care preparation & USA & ND & 2462 & ND & 1120 & ND \\
\hline Cleansing facial soap & Face and neck care & Korea & ND & $<10$ & ND & $<10$ & ND \\
\hline $\begin{array}{l}\text { Face cleansing and } \\
\text { brightening }\end{array}$ & Face and neck care & India & ND & $<10$ & ND & $<10$ & ND \\
\hline
\end{tabular}


Table 4. Cont

\begin{tabular}{|c|c|c|c|c|c|c|c|}
\hline Name of the Product & Main Category & Country of Origin & $\begin{array}{l}\text { Staphylococcus } \\
\text { aureus (per g) }\end{array}$ & $\begin{array}{l}\text { Yeast and } \\
\text { Mold CFU/g }\end{array}$ & $\begin{array}{c}\text { Candida } \\
\text { albicans (per g) }\end{array}$ & $\begin{array}{c}\text { Aerobic Mesophilic } \\
\text { Bacteria CFU/g }\end{array}$ & $\begin{array}{c}\text { Pseudomonas } \\
\text { aeruginosa (per g) }\end{array}$ \\
\hline Hair loss shampoo & Hair and scalp care & UAE & ND & $<10$ & ND & $<10$ & ND \\
\hline Sunscreen & Body care preparation & USA & ND & $<10$ & ND & $<10$ & ND \\
\hline Mouth rinse & Oral hygiene product & EU & ND & $<10$ & ND & $<10$ & ND \\
\hline Face mask & Face and neck care & Middle East & ND & $<10$ & ND & $<10$ & ND \\
\hline Hair styling gel & Hair and scalp care & China & ND & $<10$ & ND & $<10$ & ND \\
\hline Toothpaste and mouth rinse & Oral hygiene product & USA & ND & $<10$ & ND & $<10$ & ND \\
\hline Facial cleanser & Face and neck care & India & ND & $<10$ & ND & $<10$ & ND \\
\hline Hair styling gel & Hair and scalp care & Middle East & ND & 2345 & ND & 1700 & ND \\
\hline Soap & Body care preparation & Middle East & ND & $<10$ & ND & $<10$ & ND \\
\hline Facial scrub & Face and neck care & $\mathrm{EU}$ & ND & $<10$ & ND & $<10$ & ND \\
\hline Facial scrub & Face and neck care & Middle East & ND & $<10$ & ND & 4200 & ND \\
\hline Mouthwash & Oral hygiene product & UAE & ND & $<10$ & ND & $<10$ & ND \\
\hline Moisturizing body lotion & Body care preparation & EU & ND & 2000 & ND & $<10$ & ND \\
\hline Hair styling gel & Hair and scalp care & UAE & ND & $<10$ & ND & $<10$ & ND \\
\hline Toothpaste & Oral hygiene product & UAE & ND & $<10$ & ND & $<10$ & ND \\
\hline Face foundation & Face and neck care & USA & ND & $<10$ & ND & $<10$ & ND \\
\hline Mouthwash & Oral hygiene product & USA & ND & 1239 & ND & $<10$ & ND \\
\hline Face cleaning water & Face and neck care & Korea & ND & $<10$ & ND & $<10$ & ND \\
\hline Antistain body cream & Body care preparation & Middle East & ND & 1246 & ND & 5780 & ND \\
\hline Firming and wrinkle removal & Body care preparation & Middle East & ND & $<10$ & ND & $<10$ & ND \\
\hline Body cream & Body care preparation & Middle East & ND & $<10$ & ND & $<10$ & ND \\
\hline Body cream & Body care preparation & USA & ND & $<10$ & ND & $<10$ & ND \\
\hline Face wipe off fleck & Face and neck care & Middle East & ND & $<10$ & ND & $<10$ & ND \\
\hline Whitening skin cream & Body care preparation & Middle East & ND & $<10$ & ND & $<10$ & ND \\
\hline Extensions volume mascara & Eye care & China & ND & $<10$ & ND & $<10$ & ND \\
\hline Fluoride toothpaste & Oral hygiene product & EU & ND & $<10$ & ND & $<10$ & ND \\
\hline Toothpaste & Oral hygiene product & China & ND & $<10$ & ND & $<10$ & ND \\
\hline Toothpaste & Oral hygiene product & China & ND & $<10$ & ND & $<10$ & ND \\
\hline Talc body powder & Body care preparation & UAE & ND & $<10$ & ND & 200 & ND \\
\hline Talc body powder & Body care preparation & UAE & ND & 1235 & ND & 8965 & ND \\
\hline Talc body powder & Body care preparation & UAE & ND & $<10$ & ND & $<10$ & ND \\
\hline Talc body powder & Body care preparation & UAE & ND & $<10$ & ND & 400 & ND \\
\hline Talc body powder & Body care preparation & UAE & ND & $<10$ & ND & 600 & ND \\
\hline Talc body powder & Body care preparation & UAE & ND & 1872 & ND & $<10$ & ND \\
\hline Talc body powder & Body care preparation & UAE & ND & $<10$ & ND & $<10$ & ND \\
\hline Talc body powder & Body care preparation & UAE & ND & 100 & ND & 1200 & ND \\
\hline
\end{tabular}


Table 4. Cont

\begin{tabular}{|c|c|c|c|c|c|c|c|}
\hline Name of the Product & Main Category & Country of Origin & $\begin{array}{l}\text { Staphylococcus } \\
\text { aureus (per g) }\end{array}$ & $\begin{array}{l}\text { Yeast and } \\
\text { Mold CFU/g }\end{array}$ & $\begin{array}{c}\text { Candida } \\
\text { albicans (per g) }\end{array}$ & $\begin{array}{c}\text { Aerobic Mesophilic } \\
\text { Bacteria CFU/g }\end{array}$ & $\begin{array}{c}\text { Pseudomonas } \\
\text { aeruginosa (per g) }\end{array}$ \\
\hline Talc body powder & Body care preparation & UAE & ND & 100 & ND & 1500 & ND \\
\hline Hair styling gel & Hair and scalp care & India & ND & 700 & ND & 21,000 & ND \\
\hline Henna & Hair and scalp care & India & ND & $<10$ & ND & $<10$ & ND \\
\hline Body oil & Body care preparation & EU & ND & $<10$ & ND & $<10$ & ND \\
\hline Sun cream & Body care preparation & Korea & ND & $<10$ & ND & $<10$ & ND \\
\hline Body oil & Body care preparation & Korea & ND & $<10$ & ND & $<10$ & ND \\
\hline Face scrub & Face and neck care & India & ND & $<10$ & ND & $<10$ & ND \\
\hline Deodorant powder & Body care preparation & EU & ND & $<10$ & ND & 1800 & ND \\
\hline Face cream & Face and neck care & EU & ND & $<10$ & ND & $<10$ & ND \\
\hline Eyeliner & Eye care & EU & ND & $<10$ & ND & $<10$ & ND \\
\hline Milk body mask & Body care preparation & Korea & ND & $<10$ & ND & $<10$ & ND \\
\hline Fragrance talc body powder & Body care preparation & USA & ND & $<10$ & ND & $<10$ & ND \\
\hline Mouthwash & Oral hygiene product & Korea & ND & $<10$ & ND & $<10$ & ND \\
\hline Dead Sea concentrated water & Body care preparation & Middle East & 0 & $<10$ & ND & $<10$ & ND \\
\hline Eyeliner & Eye care & India & 0 & $<10$ & ND & $<10$ & ND \\
\hline Eyebrow powder & Eye care & China & 0 & $<10$ & ND & $<10$ & ND \\
\hline Eyes brow gel & Eye care & EU & 0 & 1287 & ND & $<10$ & ND \\
\hline Facial balancing cleanser & Face and neck care & India & 0 & $<10$ & ND & $<10$ & ND \\
\hline Hair conditioner & Hair and scalp care & USA & 0 & $<10$ & ND & $<10$ & ND \\
\hline Face powder & Face and neck care & EU & 0 & $<10$ & ND & $<10$ & ND \\
\hline Facial argan oil scrub & Face and neck care & UAE & 0 & $<10$ & ND & $<10$ & ND \\
\hline Detoxifying scrub & Body care preparation & UAE & 0 & $<10$ & ND & $<10$ & ND \\
\hline Hair oil & Hair and scalp care & India & 0 & $<10$ & ND & $<10$ & ND \\
\hline Heat powder & Body care preparation & India & 0 & 300 & ND & 1900 & ND \\
\hline Face cleansing gel & Face and neck care & UAE & 0 & $<10$ & ND & $<10$ & ND \\
\hline Under eye cream & Eye care & UAE & 0 & $<10$ & ND & $<10$ & ND \\
\hline Shampoo & Hair and scalp care & $\mathrm{EU}$ & 0 & $<10$ & ND & $<10$ & ND \\
\hline Shampoo & Hair and scalp care & USA & 0 & $<10$ & ND & $<10$ & ND \\
\hline Toothpaste & Oral hygiene product & USA & 0 & 7623 & ND & 1234 & ND \\
\hline Facial scrub & Face and neck care & UAE & 0 & $<10$ & ND & $<10$ & ND \\
\hline
\end{tabular}


Table 5. Incidence of microbial contamination according to sample characteristics.

\begin{tabular}{cccc}
\hline & \multicolumn{3}{c}{ Incidence of Microbial Contamination } \\
\cline { 2 - 4 } & Aerobic Mesophilic Bacteria & Yeast and Mold & All \\
\hline Total & $15(15 \%)$ & $13(13 \%)$ & $19(19 \%)$ \\
Body care preparations & Categories & & \\
Eye care & $8(20.5 \%)$ & $6(15.4 \%)$ & $10(25.6 \%)$ \\
Face and neck care & 0 & $1(12.5 \%)$ & $1(12.5 \%)$ \\
Hair and scalp care & $2(9.5 \%)$ & $1(4.8 \%)$ & $2(9.5 \%)$ \\
Oral hygiene products & $4(19.0 \%)$ & $3(14.3 \%)$ & $4(19 \%)$ \\
$p$-Value & $1(9.1 \%)$ & $2(18.2 \%)$ & $2(18.2 \%)$ \\
& 0.492 & 0.782 & 0.633 \\
China & Country of origin & 0 & \\
EU & $1(6.7 \%)$ & $2(13.3 \%)$ & $3(20.0 \%)$ \\
India & $4(28.6 \%)$ & $2(14.3 \%)$ & $4(28.6 \%)$ \\
Korea & 0 & 0 & 0 \\
Middle East & $3(30.0 \%)$ & $2(20.0 \%)$ & $3(30.0 \%)$ \\
UAE & $4(12.5 \%)$ & $3(9.4 \%)$ & $5(15.6 \%)$ \\
USA & $3(25.0 \%)$ & $4(33.3 \%)$ & $4(33.3 \%)$ \\
$p$-Value & 0.191 & 0.257 & 0.281 \\
\hline
\end{tabular}

\section{Discussion}

In recent years, concern has been increasing regarding the biological contamination of cosmetic/personal care products. As the consumption of such products has increased, considerable research has been undertaken to evaluate the microbial contamination in these products. The number of people buying these products has risen, and the size of the market has expanded more quickly than the population. This research looked at the levels of microbial contamination in cosmetic/personal care products offered to the market in the UAE and assessed the most important risk factors causing this type of contamination.

In this study, 19 of the 100 samples (19\%) were shown to carry some level of microbiological risk. First, 15 samples (15\%) displayed aerobic mesophilic bacteria contamination. The levels of contamination with colony-forming units of these microorganisms were between 200 and $8965 \mathrm{CFU} / \mathrm{g}$ for talcum powder, $7623 \mathrm{CFU} / \mathrm{g}$ for toothpaste, between 700 and $2345 \mathrm{CFU} / \mathrm{g}$ for hair gel, between 1120 and $5780 \mathrm{CFU} / \mathrm{g}$ for body care preparations, between 4200 and $6876 \mathrm{CFU} / \mathrm{g}$ for facial/neck care products, and between 500 and 57,000 CFU/g for henna products. Past research has revealed similar problems of microbial contamination with aerobic mesophilic bacteria in both new and partly used cosmetics $[11,12]$.

Thirteen of the 100 samples under analysis in this study (13\%) exhibited yeast and mold contamination. The levels of total colony-forming units were between 100 and $1872 \mathrm{CFU} / \mathrm{g}$ for talcum powder, between 1239 and $7623 \mathrm{CFU} / \mathrm{g}$ for oral hygiene products, $1287 \mathrm{CFU} / \mathrm{g}$ for eyebrow gel, between 700 and $2345 \mathrm{CFU} / \mathrm{g}$ for hair gel, between 300 and $2462 \mathrm{CFU} / \mathrm{g}$ for body care preparations, $2369 \mathrm{CFU} / \mathrm{g}$ for facial moisturizer, and between 100 and $7500 \mathrm{CFU} / \mathrm{g}$ for henna products. These findings agree with past research in which mold and yeast were found in certain tested cosmetic products $[8,9,13]$. However, other research found no mold or yeast in any of their product samples [14].

Microbiological contamination of cosmetic/personal care products can be caused by the conditions/environment employed for growing and harvesting raw materials, how these materials are stored and transported, and/or the manufacturing environment used for the final product. Therefore, high standards of manufacturing protocols must be adhered to, and all raw materials, especially those that originate naturally, should be analyzed for contamination beforehand and checked that they fall within acceptable parameters. Every area susceptible to contamination should be identified and suitable controls should be introduced. Interestingly, our findings showed that talcum powder was one of the most contaminated products, exhibiting yeast and mold and aerobic mesophilic bacterial contamination. 
Such products are frequently exposed to air. Additionally, the natural ingredients that comprise these products, including bentonite, Fuller's earth, and talc, could increase the contamination levels [15]. Another significant concern surrounding this research was the high levels of contamination of yeast and mold and aerobic mesophilic bacteria in cosmetic creams. These levels are due to the fact that cosmetic creams have rich textures created using growth factors, essential minerals, and high moisture levels; with a wide spread of organic and inorganic compounds, this creates a good environment for microbes to grow [16-18]. Cosmetic products that have a high moisture content are those that are most likely to have microbial contamination; consideration should be given to changing the ingredients of these products, or they may threaten consumer health $[19,20]$. In terms of other forms of microbial contamination, this research found positive outcomes, with no samples displaying any contamination from Pseudomonas aeruginosa, Candida albicans, Staphylococcus aureus, or Escherichia coli. These findings do not match those of some European studies, which found that the majority of cosmetic contamination was caused by Gram-negative bacteria, chiefly Pseudomonas aeruginosa and Enterobacter gergoviae; Staphylococcus aureus was the most frequently identified of the Gram-positive bacteria. The same research found that Candida albicans was the most prevalent fungus [2]. The fact that products offered for sale in the UAE have such low levels of microbiological and other contamination may be attributed to the robust regulatory provisions in the UAE. All cosmetic/personal care products offered on the market are obliged by municipalities and health regulators to register so that they can be checked for safety, effectiveness, and quality. Furthermore, microbial contamination remains a central reason for the recall of products worldwide, especially in developing nations in the tropics [21]. The results of this study showed that products from India, the Middle East, and the USA had the highest levels of microbial contamination. In the European study previously mentioned, almost $50 \%$ of the products that were found to have microbiological risks were produced in one of the following five nations: Germany (18.27\%), France (7.69\%), the Czech Republic (6.73\%), Greece (6.73\%), and India (6.73\%). Therefore, it is essential that preservative systems [20-23] are improved to prevent microorganism contaminants from growing or being manufactured, stored, and employed by consumers; the use of noninvasive packaging would also improve matters [24,25].

\section{Conclusions}

To date, no study has investigated the microbial contamination of cosmetic/personal care products offered for sale in the UAE. Furthermore, a quantitative analysis of international reports regarding this issue is lacking. This information could be useful for manufacturers, regulators, and health care providers, who may need to treat patients experiencing skin infections caused by organisms of unknown provenance. This study is a significant contribution to the knowledge regarding the distribution of microbiota within cosmetic products. Manufacturers should be prioritizing the ability to guarantee that their cosmetics contain appropriate preservatives. The findings of this study could be helpful for those producing novel challenge tests in experiments to develop guaranteed ways of preserving cosmetic products by identifying the most prevalent types of bacteria. These results have also indicated that it is vital that manufacturing facilities, equipment, tools, storage containers, etc., should all adhere to the highest standards of hygiene. To reduce contamination levels, manufacturers must adhere to all good manufacturing practice (GMP) protocols. All raw materials should meet an agreed standard and be properly tested for quality control. Further measures that manufacturers could take against contamination are taking control of validating processes, introducing training for workers, and revising and enhancing cleaning/sanitation procedures.

Cosmetic microbiology is a complicated field because there are numerous different formulations, manufacturing processes, and products that are used by a wide variety of consumers in many different environments. This study revealed two important elements: (1) Cosmetics are exposed to a wide range of possible contaminants in the manufacturing process, especially those carried by raw materials, and (2) moisture content (water) is the most frequently included ingredient that poses clear difficulties. However, even apparently benign substances, such as talc, may contain hazardous levels of pathogens. 
The manufacturers of cosmetic/personal care products must formulate and put into practice rigorous protocols for quality control and assurance, and these should be monitored by government regulation. Both the quality and safety of cosmetic/personal care products must be more strictly regulated concerning reporting mechanisms for issues of concern, research, education, regulatory procedures, and GMP.

Author Contributions: Conceptualization, A.A.J. and S.S.A.-H.; methodology, M.S.; software, A.A.J.; validation, S.H.Z. and M.S.; formal analysis, A.A.J.; investigation, S.S.A.-H.; resources, S.H.Z.; data curation, A.A.J.; writing—original draft preparation, S.S.A.-H.; writing—review and editing, M.S.; visualization, A.A.J.; supervision, S.H.Z. All authors have read and agreed to the published version of the manuscript.

Funding: This research received no external funding.

Conflicts of Interest: The authors declare no conflict of interest.

\section{References}

1. European Parliament, Council of the European Union. Regulation (EC) No 1223/2009 of the European Parliament and of the Council of 30 November 2009 on Cosmetic Products; European Parliament, Council of the European Union: Brussels, Belgium, 2009.

2. Michalek, I.M.; John, S.M.; Caetano dos Santos, F.L. Microbiological contamination of cosmetic products-observations from Europe, 2005-2018. J. Eur. Acad. Dermatol. Venereol. 2019, 33, 2151-2157. [CrossRef] [PubMed]

3. Kligman, A.M. Cosmeceuticals as a third category. Cosmet. Toilet 1998, 113, 33-41.

4. Vermeer, B.J.; Gilchrest, B.A. Cosmeceuticals: A proposal for rational definition, evaluation and regulation. Arch. Dermatol. 1996, 132, 337-340. [CrossRef] [PubMed]

5. Behravan, J.; Bazzaz, F.; Malaekeh, P. Survey of bacteriological contamination of cosmetic creams in Iran (2000). Int. J. Dermatol. 2005, 44, 482-485. [CrossRef] [PubMed]

6. Becks, V.E.; Lorenzoni, N.M. Pseudomonas aeruginosa outbreak in a neonatal intensive care unit: A possible link to contaminated hand lotion. Am. J. Infect. Control 1995, 23, 396-398. [CrossRef] [PubMed]

7. The Scientific Committee on Consumers Safety, Directorate-General for Health and Consumer Protection of the European Commission. The SSCS's Notes of Guidance for the Testing of Cosmetic Ingredients and Their Safety Evaluation, 10th ed.; European Comission: Brussels, Belgium, 2018.

8. Anelich, L.E.; Korsten, L. Survey of micro-organisms associated with spoilage of cosmetic creams manufactured in South Africa. Int. J. Cosmet. Sci. 1996, 18, 25-40. [CrossRef] [PubMed]

9. Dadashi, L.; Dehghanzadeh, R. Investigating incidence of bacterial and fungal contamination in shared cosmetic kits available in the women beauty salons. Health Promot. Perspect. 2016, 6, 159-163. [CrossRef] [PubMed]

10. Lundov, M.D.; Zacharian, C. Recall of microbiologically contaminated cosmetics is Eu from 2005 to May 2008. Int. J. Cosmet. Sci. 2008, 30, 471-474. [CrossRef] [PubMed]

11. Scientific Committee on Consumer Products. The SCCP's Notes of Guidance for the Testing of Cosmetic Ingredients and Their Safety Evaluation. 2006. Available online: http://ec.europa.eu/health/scientific committees/consumer_safety/docs/sccs_s_006.pdf (accessed on 13 June 2020).

12. Nasser, L.A. Fungal profiles isolated from open and used cosmetic products collected from different localities in Saudi Arabia. Saudi J. Biol. Sci. 2008, 15, 121-128.

13. Flores, M.; Morillo, M.; Crespo, M.L. Deterioration of raw materials and cosmetic products by preservative resistant microorganisms. Int. Biodeterior. Biodegrad. 1997, 40, 157-160. [CrossRef]

14. Abaas, I.S.; Mohammed, H.R.; Majeed, A.H. The microbial contamination study of some herbal cosmatics products used in traditional medicine in Iraq. Karbala J. Pharm. Sci. 2013, 6, 132-140.

15. Kulkarni, S.B.; Bajpai, N.D.; Meghre, V.S. Evaluation of dome marketed facepacks and cakes for microbial load. Asian J. Microbiol. Biotechnol. Environ. Sci. 2011, 13, 213-216.

16. Kabara, J.J.; Orth, D.S. (Eds.) Preservative-free and self-preserving cosmetics and drugs. In Principles for Product Preservation; Marcel Dekker: New York, NY, USA, 1997; Volume 31, pp. 1-14.

17. Wedderburn, D.L. Preservation of emulsions against microbial attack. In Advances in Pharmaceutical Sciences; Bean, A.H., Beckett, J.E., Carless, H.S., Eds.; Academic Press: London, UK, 1964; Volume 1, pp. 195-268. 
18. Elmorsy, T.H.; Hafez, E.A. Microbial contamination of some cosmetic preparations in Egypt. J. Agric. Technol. 2016, 12, 471-481.

19. Steinberg, D.C. Preservatives for Cosmetics, 2nd ed.; Allured Publishing: Carol Stream, IL, USA, 2006; pp. 2-7.

20. Lundov, M.D.; Moesby, L.; Zachariae, C.; Johansen,J.D. Contamination versus preservation of cosmetics: A review on legislation, usage, infections, and contact allergy. Contact Dermat. 2009, 60, 70-78. [CrossRef] [PubMed]

21. Okeke, I.N.; Lamikanra, A. Bacteriological quality of skin-moisturizing creams and lotions distributed in a tropical developing country. J. Appl. Microbiol. 2001, 23, 922-928. [CrossRef] [PubMed]

22. Farrington, J.K.; Martz, E.L.; Wells, S.J.; Ennis, C.C.; Holder, J.; Levchuk, J.W.; Avis, K.E.; Hoffman, P.S.; Hitchins, A.D.; Madden, J.M. Ability of laboratory methods to predict in-use efficacy of antimicrobial preservatives in an experimental cosmetic. Appl. Environ. Microbiol. 1994, 1, 4553-4558. [CrossRef] [PubMed]

23. Lintner, K.; Genet, V. A physical method for preservation of cosmetic products. Int. J. Cosmet. Sci. 1998, 20, 103-115. [CrossRef] [PubMed]

24. Brannan, D.K.; Dille, J.C. Type of closure prevents microbial contamination of cosmetics during consumer use. Appl. Environ. Microbiol. 1990, 1, 1476-1479. [CrossRef] [PubMed]

25. Campana, R.; Scesa, C.; Patrone, V.; Vittoria, E.; Baffone, W. Microbiological study of cosmetic products during their use by consumers: Health risk and efficacy of preservative systems. Lett. Appl. Microbiol. 2006, 43, 301-306. [CrossRef] [PubMed]

Publisher's Note: MDPI stays neutral with regard to jurisdictional claims in published maps and institutional affiliations. 